\title{
Nanoscale Imaging and Stabilization of Silica Nanospheres in Liquid Phase Transmission Electron Microscopy
}

Meijerink, Mark J.; Spiga, Cristiano; Hansen, Thomas W.; Damsgaard, Christian D.; de Jong, Krijn P.; Zeevi, Jovana

Published in:

Particle \& Particle Systems Characterization

Link to article, DOI:

$10.1002 / p p s c .201800374$

Publication date:

2019

Document Version

Peer reviewed version

Link back to DTU Orbit

Citation (APA):

Meijerink, M. J., Spiga, C., Hansen, T. W., Damsgaard, C. D., de Jong, K. P., \& Zeevi, J. (2019). Nanoscale Imaging and Stabilization of Silica Nanospheres in Liquid Phase Transmission Electron Microscopy. Particle \& Particle Systems Characterization, 36(1), [1800374]. https://doi.org/10.1002/ppsc.201800374

\section{General rights}

Copyright and moral rights for the publications made accessible in the public portal are retained by the authors and/or other copyright owners and it is a condition of accessing publications that users recognise and abide by the legal requirements associated with these rights.

- Users may download and print one copy of any publication from the public portal for the purpose of private study or research.

- You may not further distribute the material or use it for any profit-making activity or commercial gain

- You may freely distribute the URL identifying the publication in the public portal 


\section{WILEY-VCH}

\section{Article type: Full Paper}

\section{Nanoscale Imaging and Stabilization of Silica Nanospheres in Liquid Phase Transmission Electron Microscopy}

Mark J. Meijerink, Cristiano Spiga, Thomas W. Hansen, Christian D. Damsgaard, Krijn P. de Jong, Jovana Zečević*

Mark J. Meijerink, Prof. Krijn P. de Jong, Prof. Jovana Zečević

Inorganic Chemistry and Catalysis

Debye Institute of Nanomaterials Science

Utrecht University

Universiteitsweg 99

3584 CG Utrecht, The Netherlands

E-mail: J.Zecevic@uu.nl

Cristiano Spiga, Dr. Thomas W. Hansen, Dr. Christian D. Damsgaard

Center for Electron Nanoscopy

Technical University of Denmark

Fysikvej, 2800, Lyngby

Denmark

Keywords: liquid phase STEM, environmental TEM, electron beam damage, silica nanoparticles, radical scavenging

Liquid phase transmission electron microscopy (LP-TEM) is a novel and highly promising technique for the in situ study of important nanoscale processes, in particular the synthesis and modification of various nanostructures in a liquid. Destabilization of the samples, including reduction, oxidation or dissolution by interactions between electron beam, liquid and sample is still one of the main challenges of this technique. In this work we focused on amorphous silica nanospheres and the phenomena behind their reshaping and dissolution in LP-TEM. It is proposed that silica degradation is primarily the result of reducing radical formation in the liquid phase and the subsequent accelerated hydroxylation of the silica, while alterations in silica solid structure, $\mathrm{pH}$ and oxidizing species formation had limited influence. Furthermore, the presence of water vapor instead of liquid water also results in degradation of silica. Most importantly however, we show that the addition of scavengers for reducing radicals significantly improved amorphous silica stability during LP-TEM imaging. Devising 


\section{WILEY-VCH}

such methods to overcome adverse effects in LP-TEM is of the utmost importance for further development and implementation of this technique in studies of nanoscale processes in liquid.

\section{Introduction}

For decades, Transmission Electron Microscopy (TEM) has been a leading technique for investigations of nanoscale morphology and even atomic structure of a variety of materials. ${ }^{[1-}$

${ }^{4]}$ However, one of the main limitations of conventional TEM is that the sample can only be imaged in a vacuum. Although the electron beam can be utilized to drive nanoscale dynamic processes in this environment, ${ }^{[5]}$ the possibilities to study such processes taking place in gaseous or liquid environment, such as fabrication of microelectromechanical systems (MEMS) and microsupercapacitors (MSC), ${ }^{[6]}$ nanoparticle formation and catalyst synthesis, ${ }^{[7}$, ${ }^{8]}$ is severely limited. Recently developed liquid phase TEM (LP-TEM) offers a mean to overcome this challenge, allowing samples to be imaged in a liquid with nanoscale spatial resolution and high temporal resolution. ${ }^{[9-11]}$ The most popular method to perform these experiments is by utilizing the closed cell design, ${ }^{[12]}$ which encloses the sample and liquid between two silicon nitride windows in a dedicated holder, although enclosing liquids between two graphene layers ${ }^{[13,14]}$ or differential aperture pumping techniques have also been utilized. $^{[15]}$ The closed cell technique has already been employed to study nanoscale dynamic processes such as biomineralization, ${ }^{[16,17]}$ carbon nanotube degradation by macrophages, ${ }^{[18]}$ nanoparticle movement and interactions, ${ }^{[19,20]}$ electrochemical deposition and growth ${ }^{[21-23]}$ and in particular nucleation and growth induced by the electron beam. ${ }^{[24-27]}$ The majority of the published articles highlight an important challenge in liquid phase TEM, which is to distinguish electron beam induced effects from the phenomena under investigation, and ultimately to suppress these effects. Along with the beam damage already known from TEM imaging in vacuum, ${ }^{[28]}$ liquid phase TEM suffers from additional beam induced effects. ${ }^{[29]}$ The most prominent challenge being the formation of radicals and other 


\section{WILEY-VCH}

reactive species in the liquid upon electron beam irradiation, which significantly changes local chemistry. ${ }^{[30]}$ It was recently found that such a change in chemistry also affects oxides, materials usually considered quite stable under electron beam irradiation. ${ }^{[31]}$ This destabilizing effect is also seen for amorphous $\mathrm{SiO}_{2}$, an important oxide in many nanoscale applications, ${ }^{\text {[32- }}$ ${ }^{34]}$ which although stable in vacuum, is severely destabilized by electron beam induced chemistry in water. ${ }^{[35,36]}$ Specifically, it was shown that upon imaging with a scanning electron beam, silica nanospheres tended to elongate in the scanning direction of the beam and shrink significantly over time. To date however, most studies in LP-TEM focused on metallic nanoparticles, resulting in a limited understanding of oxide behavior under these conditions. To enable LP-TEM studies free from adverse electron beam effects, on not only amorphous silica, but also other metals and oxides, or possibly even utilize such beam-induced chemistry changes, ${ }^{[37]}$ it is vital to improve our understanding of these degradation phenomena. In this article, we investigate the factors contributing to the degradation of amorphous silica in LPTEM, focusing on the oxide structure and the beam-induced chemistry changes of the environment and demonstrate that the main route of degradation is related to the formation of reducing radicals in the liquid phase. In addition, using Environmental TEM (ETEM), we demonstrate that similar electron beam induced degradation phenomena takes place when water vapor instead of liquid water is present, with a strong dependence on water partial pressure. Identifying this degradation route allowed us to develop a method to mitigate electron beam induced effects by scavenging these radicals. The accomplished stabilization of amorphous silica is an important and promising step towards establishing controlled conditions for imaging nanomaterials in in situ TEM experiments.

\section{Results and Discussion}

In this study, amorphous silica spheres prepared using the Stöber method ${ }^{[38]}$ were used as a model system to establish the impact of the electron beam during the LP-TEM imaging and 


\section{WILEY-VCH}

ETEM imaging in the presence of water. The spherical shape of the particles allows to accurately track and analyze their reshaping and resizing. Three representative high angle annular dark field (HAADF)-STEM images of the silica sample, one image in vacuum and two images of the sample in liquid water, prior to and after 5 minutes of continuous electron beam scanning, are shown in Figure 1a, 1b and 1c respectively. As seen in Figure 1, silica particles vary in size, and the majority of the particles have a diameter between $60-100 \mathrm{~nm}$, but with a fraction of 20-30 nm diameter particles (see also Supporting Figure S1). As was previously reported ${ }^{[35]}$ and also visible in Figure $1 \mathrm{c}$, the scanning of the electron beam introduced elongation in the scanning direction and shrinkage of particles.

\subsection{Influence of Silica Solid Structure}

One of the possible parameters relevant for silica degradation observed in Figure $1 \mathrm{c}$ is the solid structure of the silica itself, in particular the porosity and the degree of hydroxylation of both the surface and bulk of the particles. ${ }^{[35]}$ Lowering the degree of silica condensation could result in increasing susceptibility towards excitation and destabilization by the electron beam. This would facilitate reactions with water, leading to the formation of soluble $\mathrm{Si}(\mathrm{OH})_{4}$ species thought to be responsible for the deformation and dissolution of the particles. To investigate the potential influence of the silica structure, the silica nanospheres were submitted to a heat treatment in stagnant air at temperatures ranging from $400{ }^{\circ} \mathrm{C}$ to $1000{ }^{\circ} \mathrm{C}$. By varying the temperature of the calcination step, the structural properties of the silica nanospheres were altered, with higher calcination temperatures resulting in a decrease of both porosity and number of hydroxyl groups according to literature. ${ }^{[39-41]}$

Nitrogen physisorption was performed to investigate the change in porosity and surface area of these samples (Table 1). As can be observed, upon increasing calcination temperature a significant decrease in surface area occurred, which can be partly attributed to the collapse of 


\section{WILEY-VCH}

pores, as a reduction in pore volume is also observed. Another likely contribution to the decrease in surface area is the sintering of the small $20-30 \mathrm{~nm}$ silica particles observed in Figure 1a. These small particles underwent considerable sintering with each other, but not with the larger spherical particles, which did not sinter or grow at all, as can be observed in the images and histograms in Supporting Figure S1. Although present, these smaller particles were not studied in the LP-TEM experiments as their visibility was impaired by the micron thick liquid layer.

Figure $2 \mathbf{a}$ and $\mathbf{2 b}$ show representative images of samples that were calcined at the lowest $\left(400{ }^{\circ} \mathrm{C}\right)$ and highest $\left(1000{ }^{\circ} \mathrm{C}\right)$ temperatures, before and after 33 minutes of electron beam scanning in STEM with alternating horizontal and vertical scanning direction in $\mathrm{H}_{2} \mathrm{O}(\leq 5 \mathrm{ppm}$ impurities, Sigma-Aldrich) at $225 \mathrm{kx}$ magnification and with a dose rate of $5.2 \times 10^{3} \mathrm{e}^{-} \mathrm{nm}^{-2} \mathrm{~s}^{-1}$. Images showing silica particles before each change in scanning direction and movies of the whole experiment are available in the Supporting Figure S2 and Supporting Movies 1 and 2. In accordance with previous research, ${ }^{[35]}$ the particles tended to elongate in the scanning direction of the beam, while shrinking in the direction perpendicular to that (Supporting Figure S2). The material removal rate in the perpendicular direction was found to be higher than the growth of the particles in the scanning direction, resulting in a net loss of volume. The quantification of the size change of the silica particles was performed by determining the total surface area of the TEM projection of the particles assuming a perfect ellipse.

Deformation in the z-axis perpendicular to the image plane was considered negligible, since previous work demonstrated no size change in the z-axis by imaging of the deformed particles at different tilt angles. ${ }^{[35]}$ The quantitative analysis of the particle size change averaged over 10-20 silica particles before and after each change in scanning direction is shown in Figure 2c. After 5 minutes of exposure samples calcined at higher calcination temperatures seem more stable, with even an expansion observed for the silica spheres calcined at $1000{ }^{\circ} \mathrm{C}$. This might indicate the initial hydroxylation of silica is more extensive for samples that have been 


\section{WILEY-VCH}

largely dehydroxylated. However, no statistically significant difference or trend can be observed after 5-15 minutes between silica samples calcined at different temperatures, indicating that the initial silica structure and porosity seem to be of limited influence. We tentatively propose that independent of the initial structure, the silica-water system is quickly ‘equilibrated’ to the same reactive state after which silica dissolves at similar rates.

In previous work the apparent elongation was reported to proceed through both shrinkage via dissolution of the particles parallel to the electron beam scanning direction and growth via redeposition of silica species at the sides of the particles. However, a closer look at the particles studied here indicates that dissolution is likely the prevailing cause for this shape change. As is shown in Figure 2d, growth of the particle axis in the scanning direction is limited, except for the time before the first change in scanning direction. The shrinkage of the axis perpendicular to the scanning direction on the other hand is far more significant. This indicates that material was preferentially removed from the sides of the particle aligned with the scanning direction, with only limited re-deposition at the ends of the particle. A possible explanation for this preferential removal could be that at the sides of particles aligned with the scanning direction, the beam-liquid-particle surface interface is the largest, resulting in accumulation of reactive species along that surface. For the rest of the particle, as the beam scans across it, this interface is smaller resulting in less radical accumulation and a diminished effect on the silica particles, as the lifetime of the formed radicals is just a few microseconds. ${ }^{[42]}$

\subsection{Influence of Organic Liquids}

Another possible explanation for the observed silica degradation involves the changes in local chemistry of the liquid induced by the beam. In water, this chemistry is relatively complex with many species being formed upon ionization or excitation of water molecules by the electron beam and the consequent reaction network. ${ }^{[42,43]}$ According to literature, the most 


\section{WILEY-VCH}

important species to consider in water are the $\mathrm{OH}^{-}, \mathrm{H}^{+}, \mathrm{H}_{2}$ and $\mathrm{H}_{2} \mathrm{O}_{2}$ species and the $\mathrm{e}^{-}$(aq), $\mathrm{OH} \cdot \mathrm{H} \cdot$ and $\mathrm{HO}_{2} \cdot$ radicals. All of these species could possibly interact with and destabilize the amorphous silica. In particular the formed $\mathrm{OH}^{-}$and the radicals are likely to aid in the degradation of the particles, by breaking silicon-oxygen bonds and forming soluble silica species.

To reduce the number of reactive species brought about by water radiolysis, LP-TEM imaging of silica spheres was also performed in toluene and in octane, which both have a very different radical chemistry. In these experiments, the same scanning conditions as in Figure 2 were applied with the sample of silica calcined at $800{ }^{\circ} \mathrm{C}$. In these nonpolar organic systems, the formation of ionic species is much more limited due to the significantly lower relative permittivity compared to water. This results in a much higher chance of recombination of ions formed by the electron beam and ensures that the beam-induced radical chemistry in these liquids is dominated by excitations and associated homolytic bond cleavage. ${ }^{[42,44]}$ Due to this and the preference for $\mathrm{C}-\mathrm{H}$ bond cleavage over $\mathrm{C}-\mathrm{C}$ bond cleavage, the main species produced by the electron beam are $\mathrm{H}^{\cdot}$ and $\mathrm{C}_{\mathrm{x}} \mathrm{H}_{\mathrm{y}^{*}}$, both strongly reducing radicals.

The results of these experiments are shown in Figure 3 and Supporting Figure S3. The degradation of silica in both toluene and octane is remarkably similar when compared to that of water. For toluene, no statistically significant difference is found, while for the octane a minor difference in degradation at highest accumulated dose can be observed. Considering that silica nanoparticles do not deform and degrade when imaged in vacuum, it is probable that degradation observed in water, toluene and octane is due to beam-induced liquid chemistry. The most likely explanation would be that the degradation is caused by reducing radicals, namely $\mathrm{e}^{-}{ }_{(\mathrm{aq}),} \mathrm{C}_{\mathrm{x}} \mathrm{H}_{\mathrm{y}}{ }^{*}$ and $\mathrm{H} \cdot$, the last one being the only produced species all three liquids have in common. 


\section{WILEY-VCH}

\subsection{Radical Scavenging Solutes}

To investigate the hypothesis that reducing radicals contribute to the observed degradation of silica, an additional series of experiments was performed with solutes added to water, namely acetic acid buffer, phosphoric acid buffer and potassium persulfate. Although the high dose rates encountered in LP-TEM generally result in a significantly higher number of radicals compared to radiation chemistry studies and rapid consumption of scavengers, only a very small part of the liquid is irradiated. Diffusion from outside the irradiated area can compensate for this loss up to very high dose rates, even with low concentrations. According to calculations, typical steady state concentrations of reducing radicals are $<10 \mu \mathrm{mol} \mathrm{dm}^{-3}$ in deaerated water, ${ }^{[43]}$ indicating that concentrations of $0.1 \mathrm{~mol} \mathrm{dm}^{-3}$ should be sufficient to significantly decrease steady state radical concentrations. As direct detection of radical species and their reactions is as yet not possible in TEM, only indirect evidence in the form of changing silica behavior upon the addition of radical scavengers is available. Acetic acid, along with other organic acids, is one such radical scavenger and is capable of scavenging radicals through reactions 1 and 2, which results in the elimination of $\mathrm{e}^{-}(\mathrm{aq}), \mathrm{OH} \cdot$ and $\mathrm{H} \cdot$ and the formation of the $\cdot \mathrm{CH}_{2} \mathrm{COO}(\mathrm{H})$ radical, which is known to rapidly dimerize to succinate. ${ }^{[42 \text {, }}$ 45]

$$
\mathrm{CH}_{3}-\mathrm{COO}(\mathrm{H})+\cdot \mathrm{H} / \mathrm{OH} \cdot \rightarrow \cdot \mathrm{CH}_{2} \mathrm{COO}(\mathrm{H})+\mathrm{H}_{2}(\mathrm{O})
$$

$$
2 \cdot \mathrm{CH}_{2} \mathrm{COO}(\mathrm{H}) \rightarrow\left(\mathrm{CH}_{2}\right)_{2}(\mathrm{COO}(\mathrm{H}))_{2}
$$

As can be observed in Figure 4a-c, Supporting Figure S4 and the Supporting Movies 3 and 4, the acetic acid buffer was capable of substantially stabilizing the amorphous silica nanoparticles calcined at $800{ }^{\circ} \mathrm{C}$, with a clear dose-response relation for lower concentrations. When using a concentration of $0.2 \mathrm{~mol} \mathrm{dm}^{-3}$ of acetic acid buffer, surface area of the silica 


\section{WILEY-VCH}

particles decreased by less than $10 \%$ even after 33 minutes of intense radiation, which is significantly less compared to more than $50 \%$ loss in the case of pure water. At concentrations higher than $0.2 \mathrm{~mol} \mathrm{dm}^{-3}$, this stability decreased again, although it still surpassed that of pure water. This effect is likely a result of the direct radiolysis of the acetate itself, which produces significant numbers of $\mathrm{H} \cdot$ radicals. The effects of direct radiolysis for solutes is usually not observed at low concentrations $\left(<0.1 \mathrm{~mol} \mathrm{dm}^{-3}\right)$, but at higher concentrations becomes increasingly prevalent, resulting in an optimum between scavenging and additional radical production. ${ }^{[42]}$

Besides being a scavenger for most of the radicals produced by electron beam radiolysis of water, the acetic acid buffer could also have a buffering effect, which could mitigate the influence of protons and hydroxide ions also produced upon water radiolysis, although previous work on other oxides seem to indicate increased acidity is of limited influence on dissolution kinetics. ${ }^{[31]}$ Calculations do indicate that electron beam $\mathrm{H}^{+}$yield is higher than the hydroxide yield in most aqueous liquids, which would result in a mildly acidic solution, but the local activity of the $\mathrm{OH}^{-}$ion is also higher than in pure water. ${ }^{[43]}$ As silica solubility increases with higher $\mathrm{OH}^{-}$activity, this could indicate that an acidic buffer is capable of stabilizing the particle as well. To ensure that the observed stabilizing effect is due to the reducing $\mathrm{H}$ - radicals and not due to a buffering effect of the acetate solution, the same experiment was performed with a $0.2 \mathrm{~mol} \mathrm{dm}^{-3}$ phosphoric acid buffer. The results presented in Figure 4d and Supporting Figure S5 clearly show that there was no observable difference between the phosphoric acid buffer and pure water. Furthermore, considering very similar degradation observed in aprotic organic liquids (toluene, octane), it is clear that presence or absence of $\mathrm{H}^{+}$and $\mathrm{OH}^{-}$had no impact on silica stability.

Finally, oxidizing $\cdot \mathrm{OH}$ radicals formed upon electron beam induced water radiolysis might also have an influence on the degradation of $\mathrm{SiO}_{2}$. To investigate the influence of $\cdot \mathrm{OH}$ 


\section{WILEY-VCH}

radicals, an additional experiment with a solution containing $0.1 \mathrm{~mol} \mathrm{dm}{ }^{-3}$ of potassium persulfate $\left(\mathrm{K}_{2} \mathrm{~S}_{2} \mathrm{O}_{8}\right)$ was also performed. The persulfate anion reacts as illustrated in reaction 3 , selectively scavenging $\mathrm{e}^{-}$(aq) and $\mathrm{H} \cdot$ and producing the strongly oxidizing $\cdot \mathrm{SO}_{4}{ }^{-}$radical. As the $\cdot \mathrm{OH}$ radicals are not scavenged, this results in a highly oxidizing environment with similar concentrations of $\cdot \mathrm{OH}$, but a lower concentration of reducing radicals.

$$
\mathrm{S}_{2} \mathrm{O}_{8}{ }^{2-}{ }_{(\mathrm{aq})}+\mathbf{e}^{-}{ }_{(\mathrm{aq})} / \mathrm{H} \cdot \rightarrow \mathrm{SO}_{4}{ }^{2-}{ }_{(\mathrm{aq})}+\cdot \mathrm{SO}_{4}^{-}{ }_{(\mathrm{aq})}+\mathrm{H}^{+}{ }_{(\mathrm{aq})}
$$

Figure 4d and Supporting Figure S5 clearly illustrate that the addition of potassium persulfate was also able to stabilize the silica, with a very comparable effect to that of the same concentration of acetic acid buffer. This indicates that $\cdot \mathrm{OH}$ seems to be of limited influence to the $\mathrm{SiO}_{2}$ degradation.

Another interesting observation is that the particles investigated in experiments with radical scavengers remained much more spherical than their counterparts in water. Although this can be explained partially by the shrinkage being more limited, the effect is even observed for particles still losing a significant amount of surface area, such as the $0.1 \mathrm{~mol} \mathrm{dm}^{-3} \mathrm{~K}_{2} \mathrm{~S}_{2} \mathrm{O}_{8}$.

\subsection{Environmental TEM using gaseous $\mathrm{H}_{2} \mathrm{O}$}

To further investigate the extent to which presence of water influences silica degradation during in situ STEM imaging, a series of electron beam scanning experiments was performed with the silica in vacuum and in contact with water vapor partial pressures between 0.01 and 1 mbar in a dedicated ETEM. Based on the LP-TEM study, deformation of silica was expected to some extent due to the presence of water, while shrinkage, which occurs mainly through dissolution was not expected due to the absence of a water layer in which dissolved silica species would diffuse.

As can be observed in Figure 5 and Supporting Figure 6 a single particle (Supporting Figure 6) did not change to any significant extent after 30 minutes of continuous electron beam 


\section{WILEY-VCH}

scanning, even at 1 mbar of water vapor. However, when close together particles started to sinter quite rapidly when they were in contact with water vapor, as can be seen in Supporting Movie 5. The rate of sintering seemed to be dependent on the $\mathrm{H}_{2} \mathrm{O}$ partial pressure as well, whereby an increase of water partial pressure from 0.01 mbar to 0.1 mbar and 1 mbar clearly resulted in an acceleration of sintering, as can be observed from Supporting Figure 6. The effect of water on the mobility of the $\mathrm{SiO}_{2}$ was quite pronounced, especially when comparing the experiments with and without silica drying at $600{ }^{\circ} \mathrm{C}$ for 2 hours in the TEM vacuum (Figure 5). Drying clearly lead to an appreciable difference in sintering rate, indicating that even the small amount of adsorbed water from the air can significantly influence silica behavior during electron beam scanning.

\subsection{Model of Silica Deformation and Degradation}

To understand the mechanism of silica degradation under LP-TEM conditions two important phenomena observed in this study will be considered: detrimental influence of reducing radicals formed by the electron beam-induced water radiolysis and the stabilizing effect of radical scavengers. As suggested previously, ${ }^{[35]}$ mass loss occurs primarily as a result of dissolution of silica, which in water is predominantly through formation of silicic acid or $\mathrm{Si}(\mathrm{OH})_{4}$ species. The formation of silicic acid requires hydroxylation of the silica, which usually proceeds through the opening/hydrolysis of siloxane bonds by $\mathrm{H}_{2} \mathrm{O} .{ }^{[46]}$ Earlier study showed that breaking silicon-oxygen bonds can be facilitated by low-energy electrons (300$500 \mathrm{eV}$ ) in combination with a thin layer of amorphous ice, although the mechanism was not entirely clear. ${ }^{[4]}$

Based on the results of this study, we argue that the cleavage of the siloxane bonds is likely accelerated through a reaction with reducing radicals. A possible mechanism for this is through the partial reduction of silica by a hydrogen radical through reaction 4 , which leads to the formation of a dangling bond. This dangling bond is highly reactive and can subsequently 
react with water according to reaction 5, forming another hydroxyl group and hydrogen radical.

$$
\begin{aligned}
& \equiv \mathbf{S i}-\mathbf{O}-\mathbf{S i} \equiv+\cdot \mathbf{H} \rightarrow \equiv \mathbf{S i - O H}+\equiv \mathbf{S i} \cdot \\
& \equiv \mathbf{S i} \cdot+\mathbf{H}_{2} \mathbf{O} \rightarrow \equiv \mathbf{S i}-\mathbf{O H}+\cdot \mathbf{H}
\end{aligned}
$$

A similar process is expected to occur in toluene and octane, with reaction 5 involving the hydrocarbon species or a hydrocarbon radical instead of water. This would result in the formation of organosilicon compounds with a mixture of silanol, alkoxide and organosilicon groups. These compounds are known to be kinetically stable ${ }^{[48]}$ and expected to be quite soluble as the groups attached to the silicon atom are derived from the solvent. As a result, a similar shrinkage and degradation of silica particles is expected, considering that the process proceeds via dissolution of soluble silica species. In the absence of surrounding liquid, as demonstrated in ETEM studies with water vapor, dissolved silica species are prevented from diffusing away from the particles, limiting thus the degradation to sintering and moderate shape change, which is likely the result of the increase in mobility of silica species.

Although it is possible for the electron beam to cleave the silicon-oxygen bond, ${ }^{[49]}$ it is unlikely that it would be the main mechanism, as the altering of the liquid chemistry would have far less influence than observed. Furthermore, the observed anisotropy in the shape change couldn’t be explained, since there was no difference in electron beam exposure across the particle.

\section{Conclusion}

Identifying the cause and mitigating degradation of amorphous silica and other oxide and metal particles during liquid phase TEM is crucial for enabling application of this technique 


\section{WILEY-VCH}

in studies of dynamic nanoscale processes in liquid. As shown here, the main process responsible for silica degradation is an electron beam induced local change in chemistry, both in liquid and gas phase water in contact with the silica. We propose that reducing radicals produced by the electron beam are the species responsible for this degradation, while oxidizing species, local changes in $\mathrm{pH}$ and the nature of the solid silica do not have a pronounced influence. The addition of species capable of scavenging reducing radicals remarkably lessened the degradation, to the extent that amorphous silica can be more easily used for LP-TEM investigations. Devising such a method for mitigating silica degradation is an important step for the LP-TEM technique, as it allows not only the study of $\mathrm{SiO}_{2}$ and silica-based materials in a liquid phase, but also demonstrates that a higher degree of control in LP-TEM experiments is feasible.

\section{Experimental Section}

Silica preparation: Spherical silica nanoparticles were prepared adopting the procedure from Stöber et al. ${ }^{[38]}$ In a typical experiment, a mixture of of $\mathrm{NH}_{3}$ solution $\left(11.25 \mathrm{~cm}^{3}, 30 \%\right.$, Merck) and ethanol $\left(230 \mathrm{~cm}^{3}\right)$ was heated to $35{ }^{\circ} \mathrm{C}$ in an oil bath. Tetraethyl orthosilicate $\left(17.3 \mathrm{~cm}^{3}\right.$, TEOS, 98\%, Sigma-Aldrich) was subsequently added to this mixture and then left to stir (250 RPM) at $35{ }^{\circ} \mathrm{C}$ for 16 hours. The solution was then neutralized with nitric acid (65\%, SigmaAldrich) and the liquid removed by rotary evaporation. The remaining solid was dried overnight at $120{ }^{\circ} \mathrm{C}$, followed by calcination in air at $200{ }^{\circ} \mathrm{C}$ for 2 hours, at $400{ }^{\circ} \mathrm{C}$ for 1 hour and subsequently 3 hours at the final calcination temperature, either $400{ }^{\circ} \mathrm{C}, 600{ }^{\circ} \mathrm{C}, 800{ }^{\circ} \mathrm{C}$ or $1000{ }^{\circ} \mathrm{C}$, all with a heating and cooling rate of $1.7^{\circ} \mathrm{C} \mathrm{min}^{-1}$. The resulting silica particles were spherical with diameters in the range of 20-30 nm and 60-120 nm.

Liquid cell preparation: A small amount of the prepared silica was dispersed in isopropanol ( $2 \mathrm{~cm}^{3}, 99.9 \%$, Sigma-Aldrich) and sonicated for at least 15 minutes to disperse agglomerates. A droplet of this suspension $\left(0.5 \mathrm{~mm}^{3}\right)$ was placed and left for 5 minutes to evaporate on the 


\section{WILEY-VCH}

silicon nitride $\left(\mathrm{Si}_{\mathrm{x}} \mathrm{N}_{\mathrm{y}}\right)$ layer of the large silicon liquid cell chip with a $50 \mathrm{~nm}$ thick $\mathrm{Si}_{\mathrm{x}} \mathrm{N}_{\mathrm{y}}$ window with dimensions of 20x550 $\mu \mathrm{m}$ (Protochips Inc., USA). A small silicon chip also containing a 20x550 $\mu \mathrm{m} \mathrm{Si}_{\mathrm{x}} \mathrm{N}_{\mathrm{y}}$ window and $150 \mathrm{~nm}$ gold spacers to separate the two chips, was then placed in the dedicated liquid cell TEM holder (Protochips Inc., USA), a drop of pure water $\left(1 \mathrm{~mm}^{3}\right.$, sterile-filtered, Bioreagent, $\leq 1 \mathrm{Eu} \mathrm{cm}^{-3}, \leq 5 \mathrm{ppm}$ metal impurities, SigmaAldrich) was added on top of it and the cell was subsequently assembled by placing the large silicon chip on top. In this configuration, the sample is dispersed on the top chip when the holder is inserted in the microscope for optimal spatial resolution in STEM mode ${ }^{[9]}$ Both the large and small chip were plasma cleaned in an $80 \% \mathrm{Ar} / 20 \% \mathrm{O}_{2}$ plasma for two minutes before the sample was dispersed to render the chip surface hydrophilic.

Liquid Cell TEM Experiments: Liquid cell experiments were performed using a Talos F200X (Thermo Fisher Scientific, Netherlands), operated in STEM mode at $200 \mathrm{kV}$ acceleration voltage and using an HAADF detector for imaging. The imaging was performed with a beam current of $0.21 \mathrm{nA}$, as determined by the screen current without a holder present in the electron microscope and with a camera length of $125 \mathrm{~mm}$. Images were collected with a pixel dwell time of $9.5 \mu$ s, with $1024 \times 1024$ pixel images, for a total of $10 \mathrm{~s} \mathrm{frame}^{-1}$. All experiments were performed at $225 \mathrm{kx}$ magnification, corresponding to an image size of $500 \times 500 \mathrm{~nm}$, which results in a dose rate of $5.2 \times 10^{3} \mathrm{e}^{-} \mathrm{nm}^{-2} \mathrm{~s}^{-1}$.

Each liquid cell experiment was performed in flow mode using a flow of $2 \mathrm{~mm}^{3} \mathrm{~min}^{-1}$ to prevent the buildup of gases and bubble formation. For each individual measurement, a group of particles was selected and 200 images were acquired, for a total time of approximately 33 minutes. The scanning direction was rotated by $90^{\circ}$ after image number 30, 80, 120 and 160 . The particles were assumed to be perfect ellipses throughout the entire experiment and to determine the area, the length of the long and short axis of each ellipse was measured at these image numbers, as well as in the first and last image. Only particles that were sufficiently large to be observable and remained in the field of view during the entire measurement were 


\section{WILEY-VCH}

measured. For each experiment at least 2 different locations were chosen for measurements which contained at least 5 suitable particles each. In total, between 10 and 20 particles were measured and results were averaged for each different condition investigated.

All experiments were performed with the silica particles prepared at a final calcination temperature of $800{ }^{\circ} \mathrm{C}$, except for the experiments in which the effect of silica calcination temperature was studied, in which case the silica samples selected were calcined at $400{ }^{\circ} \mathrm{C}$, $600{ }^{\circ} \mathrm{C}, 800{ }^{\circ} \mathrm{C}$ and $1000{ }^{\circ} \mathrm{C}$. The experiments were performed in ultrapure water $(\leq 5 \mathrm{ppm}$ metal impurities, Sigma-Aldrich), toluene ( $\geq 99.7 \%$, Sigma-Aldrich) or octane ( $\geq 99 \%$, SigmaAldrich). All solutions used were prepared using ultrapure water. Solutions containing 0.1 mol dm${ }^{-3}, 0.2 \mathrm{~mol} \mathrm{dm}{ }^{-3}, 0.5 \mathrm{~mol} \mathrm{dm}^{-3}$ or $1.0 \mathrm{~mol} \mathrm{dm}^{-3}$ of acetic acid were prepared by addition of the corresponding amount of acetic acid ( $\geq 99.5 \%$, Sigma-Aldrich) and half of the corresponding molar ratio of $\mathrm{NaOH}$ ( $\geq 99 \%$, Sigma-Aldrich) to ultrapure water to obtain a 1:1 buffer of approximately $\mathrm{pH} 4.5$. The $0.2 \mathrm{~mol} \mathrm{dm}^{-3}$ phosphoric acid ( $\geq 99.9 \%$, Sigma-Aldrich) solution was prepared with the same method, resulting in a $\mathrm{pH}$ of approximately 2 . The 0.1 mol dm ${ }^{-3} \mathrm{~S}_{2} \mathrm{O}_{8}{ }^{2-}$ solution was prepared by dissolving solid $\mathrm{K}_{2} \mathrm{~S}_{2} \mathrm{O}_{8}(\geq 99 \%$, Sigma-Aldrich) in ultrapure water and care was taken to prepare the solution no more than 1 day in advance to prevent significant decomposition of the persulfate.

Environmental TEM experiments: The Environmental TEM (ETEM) experiments were performed using a Wildfire heating holder (DENSsolutions, Netherlands) and a heating chip with silicon nitride windows. The heating chip was plasma cleaned for 2 minutes in a 20 $\mathrm{Vol} \% \mathrm{O}_{2} / 80 \mathrm{Vol} \%$ Ar plasma prior to loading. A drop of a suspension (1.5 $\mathrm{mm}^{3}$ ) of the silica nanospheres calcined at $800{ }^{\circ} \mathrm{C}$ in isopropanol was then placed on the heating chip and left to evaporate for 5 minutes.

The ETEM experiments were performed in a dedicated Titan (Thermo Fisher Scientific, Netherlands) microscope modified for ETEM studies. All experiments were performed in STEM mode at $300 \mathrm{kV}$ acceleration voltage, with a beam current of $0.21 \mathrm{nA}$. Both the bright 


\section{WILEY-VCH}

field (BF) and high angle annular dark field (HAADF) detectors were used. For the HAADF detector, a camera length of either 115 or $165 \mathrm{~mm}$ was used to optimize resolution. Images were collected with a pixel dwell time of $9.5 \mu \mathrm{s}$, with 1024x1024 pixel images, for a total of $10 \mathrm{~s}$ frame ${ }^{-1}$. All experiments were also performed at $225 \mathrm{kx}$ magnification, corresponding to an image size of 500x500 nm, which results in a dose rate of $5.2 \times 10^{3} \mathrm{e}^{-} \mathrm{nm}^{-2} \mathrm{~s}^{-1}$.

For all ETEM experiments, a suitable particle or group of particles was selected and then subjected to continuous scanning for 180 images, corresponding to 30 minutes, or until all particles disappeared from the field of view as a result of electrostatic charging. Samples were scanned in vacuum ( $\left.10^{-7} \mathrm{mbar}\right)$ at room temperature both before and after being heated at $600{ }^{\circ} \mathrm{C}$ for 2 hours inside the column to remove any adsorbed moisture. Afterwards, the water vapor pressure was increased in steps up to 1 mbar and scanning experiments were performed at $0.01,0.1$ and 1 mbar of water partial pressure at room temperature.

\section{Supporting Information}

Supporting Information is available from the Wiley Online Library or from the author and contains additional data on the particle size distribution and structure of all silica nanospheres (Figure S1), liquid cell HAADF-STEM images used for the data point measurements (Figures S2-S5) and additional images on the sintering speed dependence on $\mathrm{H}_{2} \mathrm{O}$ partial pressure in the ETEM experiments (Figure S6).

Also available are five movies of silica nanoparticles being exposed to the electron beam, with movie M1, M2 and M3 showing particles calcined at $400^{\circ} \mathrm{C}, 1000{ }^{\circ} \mathrm{C}$ and $800{ }^{\circ} \mathrm{C}$ in $\mathrm{H}_{2} \mathrm{O}$ respectively. In movie M4, limited degradation of particles in $0.2 \mathrm{~mol} \mathrm{dm}^{-3}$ acetic acid is displayed and in movie M5, silica nanoparticles sintering under the influence of the electron beam in 1 mbar $\mathrm{H}_{2} \mathrm{O}$ is shown.

\section{Acknowledgements}

The authors gratefully acknowledge J.D. Meeldijk for technical assistance with the electron microscope, L. Weber for the N2 physisorption measurements and R. van den Berg for providing help with synthesis of silica samples. Furthermore, the authors wish to thank D.M. Bartels for the discussions regarding the radical chemistry of all species involved in this work. K.P. de Jong and M.J. Meijerink acknowledge funding from the European Research Council, an EU FP7 ERC Advanced Grant no. 338846. J. Zečević acknowledges financial support by Netherlands Organization for Scientific Research (NWO), Veni Grant no. 722.015.010. C. Spiga and C.D. Damsgaard acknowledge funding the Danish Research Council for Technology and Production (FTP) grant no. 4005-00293. 


\section{WILEY-VCH}

Received: ((will be filled in by the editorial staff))

Revised: ((will be filled in by the editorial staff)) Published online: ((will be filled in by the editorial staff))

\section{References}

[1] C. B. Carter, D. B. Williams, Transmission electron microscopy, Springer-Verlag US, 2009.

[2] C. Gómez-Navarro, J. C. Meyer, R. S. Sundaram, A. Chuvilin, S. Kurasch, M. Burghard, K. Kern, U. Kaiser, Nano Lett. 2010, 10, 1144.

[3] F. Gramm, C. Baerlocher, L. B. McCusker, S. J. Warrender, P. A. Wright, B. Han, S. B. Hong, Z. Liu, T. Ohsuna, O. Terasaki, Nature 2006, 444, 79.

[4] C. Wang, D. Van der Vliet, K. L. More, N. J. Zaluzec, S. Peng, S. Sun, H. Daimon, G. Wang, J. Greeley, J. Pearson, A. P. Paulikas, G. Karapetrov, D. Strmcnik, N. M. Markovic, V. R. Stamenkovic, Nano Lett. 2010, 11, 919.

[5] J. Li, J. Chen, H. Wang, N. Chen, Z. Wang, L. Guo, F. L. Deepak, Advanced Science 2018, 5, 1700992.

[6] J. Han, Y. C. Lin, L. Chen, Y. C. Tsai, Y. Ito, X. Guo, A. Hirata, T. Fujita, M. Esashi, T. Gessner, M. Chen, Advanced Science 2015, 2, 1500067.

[7] P. Munnik, P. E. de Jongh, K. P. de Jong, Chem. Rev. 2015, 115, 6687.

[8] J. Zečević, G. Vanbutsele, K. P. de Jong, J. A. Martens, Nature 2015, 528, 245.

[9] N. De Jonge, F. M. Ross, Nat. Nanotechnol. 2011, 6, 695.

[10] D. Li, M. H. Nielsen, J. J. De Yoreo, Journal 2013, Volume 532, 147.

[11] J. M. Grogan, N. M. Schneider, F. M. Ross, H. H. Bau, J. Indian Inst. Sci. 2012, 92,

295.

[12] M. J. Williamson, R. M. Tromp, P. M. Vereecken, R. Hull, F. M. Ross, Nat. Mater. 2003, 2, 532.

[13] J. M. Yuk, J. Park, P. Ercius, K. Kim, D. J. Hellebusch, M. F. Crommie, J. Y. Lee, A. Zettl, A. P. Alivisatos, Science 2012, 336, 61.

[14] X. Ye, M. R. Jones, L. B. Frechette, Q. Chen, A. S. Powers, P. Ercius, G. Dunn, G. M. Rotskoff, S. C. Nguyen, V. P. Adiga, A. Zettl, E. Rabani, P. L. Geissler, A. P. Alivisatos, Science 2016, 354, 874.

[15] L. L. Dai, R. Sharma, C.-y. Wu, Langmuir 2005, 21, 2641.

[16] C. T. Hendley, J. Tao, J. A. M. R. Kunitake, J. J. De Yoreo, L. A. Estroff, MRS Bull. 2015, 40, 480.

[17] P. J. M. Smeets, K. R. Cho, R. G. E. Kempen, N. A. J. M. Sommerdijk, J. J. De Yoreo, Nat. Mater. 2015, 14, 394.

[18] D. Elgrabli, W. Dachraoui, C. Ménard-Moyon, X. J. Liu, D. Bégin, S. Bégin-Colin, A. Bianco, F. Gazeau, D. Alloyeau, ACS Nano 2015, 9, 10113.

[19] H. Zheng, S. A. Claridge, A. M. Minor, A. P. Alivisatos, U. Dahmen, Nano Lett. 2009, 9, 2460.

[20] E. S. Pohlmann, K. Patel, S. Guo, M. J. Dukes, Z. Sheng, D. F. Kelly, Nano Lett. 2015, 15, 2329.

[21] A. Radisic, P. M. Vereecken, J. B. Hannon, P. C. Searson, F. M. Ross, Nano Lett. 2006, 6, 238.

[22] R. L. Sacci, N. J. Dudney, K. L. More, L. R. Parent, I. Arslan, N. D. Browning, R. R. Unocic, Chem. Commun. 2014, 50, 2104.

[23] P. Abellan, B. L. Mehdi, L. R. Parent, M. Gu, C. Park, W. Xu, Y. Zhang, I. Arslan, J.G. Zhang, C.-M. Wang, J. E. Evans, N. D. Browning, Nano Lett. 2014, 14, 1293.

[24] T. Kraus, N. de Jonge, Langmuir 2013, 29, 8427. 


\section{WILEY-VCH}

[25] K. L. Jungjohann, S. Bliznakov, P. W. Sutter, E. A. Stach, E. A. Sutter, Nano Lett. 2013, 13, 2964.

[26] W.-I. Liang, X. Zhang, K. Bustillo, C.-H. Chiu, W.-W. Wu, J. Xu, Y.-H. Chu, H. Zheng, Chem. Mater. 2015, 27, 8146.

[27] Y. Zhang, D. Keller, M. D. Rossell, R. Erni, Chem. Mater. 2017, 29, 10518.

[28] R. F. Egerton, P. Li, M. Malac, Micron 2004, 35, 399.

[29] T. J. Woehl, K. L. Jungjohann, J. E. Evans, I. Arslan, W. D. Ristenpart, N. D. Browning, Ultramicroscopy 2013, 127, 53.

[30] T. J. Woehl, P. Abellan, J. Microsc. 2017, 265, 135.

[31] Y. Lu, J. Geng, K. Wang, W. Zhang, W. Ding, Z. Zhang, S. Xie, H. Dai, F.-R. Chen, M. Sui, ACS Nano 2017, 11, 8018.

[32] M. Liong, J. Lu, M. Kovochich, T. Xia, S. G. Ruehm, A. E. Nel, F. Tamanoi, J. I. Zink, ACS Nano 2008, 2, 889.

[33] H. L. Ding, Y. X. Zhang, S. Wang, J. M. Xu, S. C. Xu, G. H. Li, Chem. Mater. 2012, 24, 4572.

[34] R. J. Archer, A. J. Parnell, A. I. Campbell, J. R. Howse, S. J. Ebbens, Advanced Science 2018, 5, 1700528.

[35] J. Zečević, J. Hermannsdörfer, T. Schuh, K. P. de Jong, N. de Jonge, Small 2017, 13, 1602466.

[36] M. W. P. Van de Put, C. C. M. C. Carcouët, P. H. H. Bomans, H. Friedrich, N. de Jonge, N. A. J. M. Sommerdijk, Small 2015, 11, 585.

[37] S. M. Rehn, M. R. Jones, ACS Energy Lett. 2018, 3, 1269.

[38] W. Stöber, A. Fink, E. Bohn, J. Colloid Interface Sci. 1968, 26, 62.

[39] L. T. Zhuravlev, Colloids Surf., A 2000, 173, 1.

[40] S. Romeis, J. Paul, M. Hanisch, V. R. Reddy Marthala, M. Hartmann, R. N. K. Taylor, J. Schmidt, W. Peukert, Part. Part. Syst. Charact. 2014, 31, 664.

[41] L. Zhang, M. D'Acunzi, M. Kappl, A. Imhof, A. van Blaaderen, H.-J. Butt, R. Graf, D. Vollmer, Phys. Chem. Chem. Phys. 2010, 12, 15392.

[42] M. Spotheim-Maurizot, M. Mostafavi, T. Douki, Radiation Chemistry: From Basics to Applications in Material and Life Sciences, EDP Sciences, 2008.

[43] N. M. Schneider, M. M. Norton, B. J. Mendel, J. M. Grogan, F. M. Ross, H. H. Bau, J. Phys. Chem. C 2014, 118, 22373.

[44] J. G. P. Calvert, James N., Jr., Photochemistry, Vol. 43, Wiley, New York 1966.

[45] M. W. G. Ross A.B., Helman W.P., Buxton G.V., Huie R.E., Neta P., Journal 1998.

[46] A. Rimola, D. Costa, M. Sodupe, J.-F. Lambert, P. Ugliengo, Chem. Rev. 2013, 113, 4216.

[47] X. Yu, E. Emmez, Q. Pan, B. Yang, S. Pomp, W. E. Kaden, M. Sterrer, S.

Shaikhutdinov, H.-J. Freund, I. Goikoetxea, R. Wlodarczyk, J. Sauer, Phys. Chem. Chem.

Phys. 2016, 18, 3755.

[48] S. Pawlenko, Organosilicon chemistry, Walter de Gruyter, 1986.

[49] K. Zheng, C. Wang, Y.-Q. Cheng, Y. Yue, X. Han, Z. Zhang, Z. Shan, S. X. Mao, M. Ye, Y. Yin, E. Ma, Nat. commun. 2010, 1, 24. 


\section{WILEY-VCH}
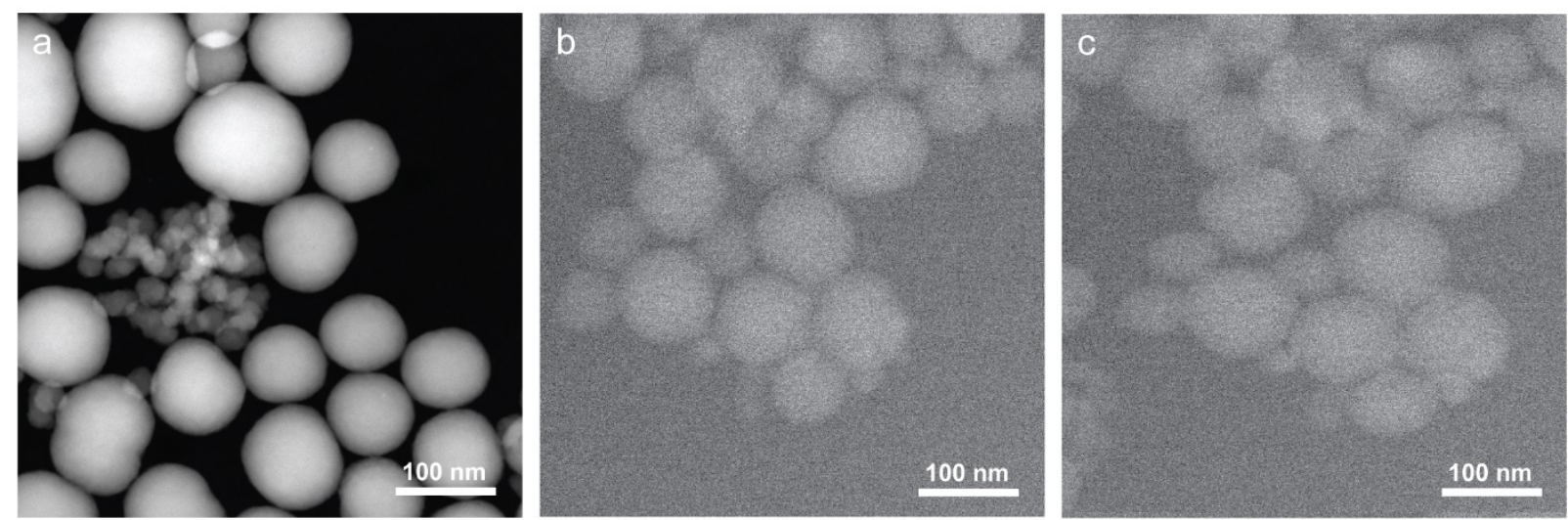

Figure 1. Representative images of the amorphous silica spheres calcined at $800{ }^{\circ} \mathrm{C}$. (a) HAADF-STEM image in vacuum, (b-c) HAADF-STEM images of amorphous silica spheres in water before (b) and after (c) 5 minutes of exposure to scanning with the electron beam from left to right.
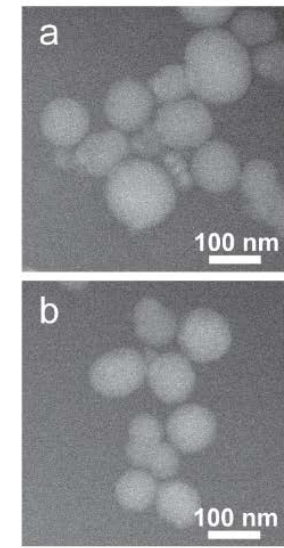
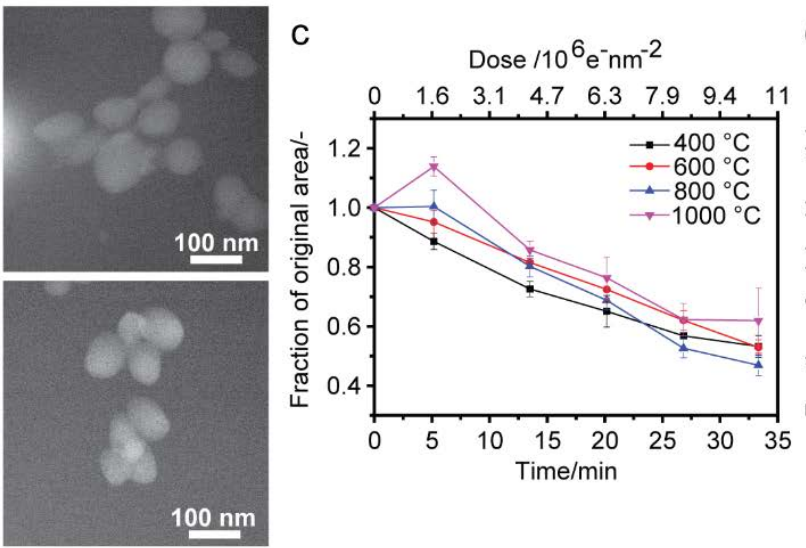

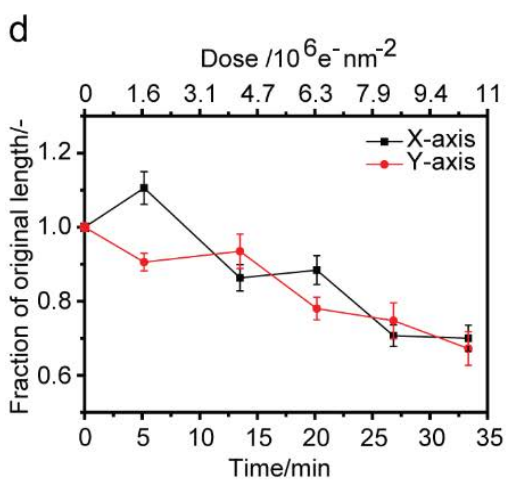

d

Figure 2. (a-b) HAADF-STEM images of silica nanospheres calcined at $400{ }^{\circ} \mathrm{C}$ (a) and 1000 ${ }^{\circ} \mathrm{C}$ (b) in water in the liquid cell before (left) and after (right) 33 minutes of electron beam scanning, changing the scanning direction between horizontal and vertical after 5, 13, 20 and 27 minutes. (c) Projected surface area relative to the initial projected surface area, averaged over 10-20 silica particles per sample as a function of time/dose. (d) Length of the x-axis and $\mathrm{y}$-axis relative to the initial lengths, averaged over 10-20 silica particles of the sample calcined at $800{ }^{\circ} \mathrm{C}$ as a function of time/dose. 


\section{WILEY-VCH}

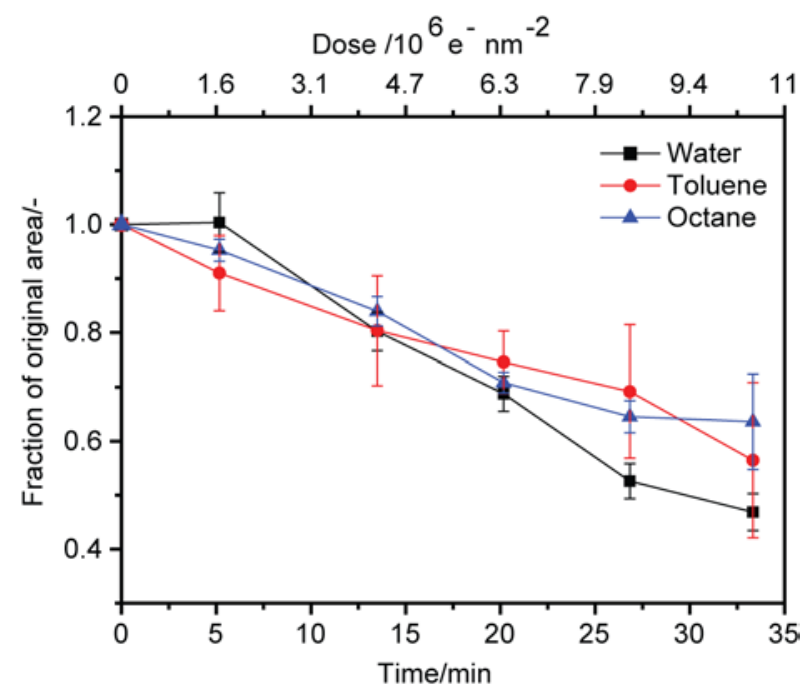

Figure 3. Projected surface area relative to the initial projected surface area, averaged over 10-20 silica particles (calcined at $800{ }^{\circ} \mathrm{C}$ ) in water, toluene and octane as a function of time/dose for continuous electron beam scanning, with the scanning direction alternated between horizontal and vertical after 5, 13, 20 and 27 minutes. 


\section{WILEY-VCH}
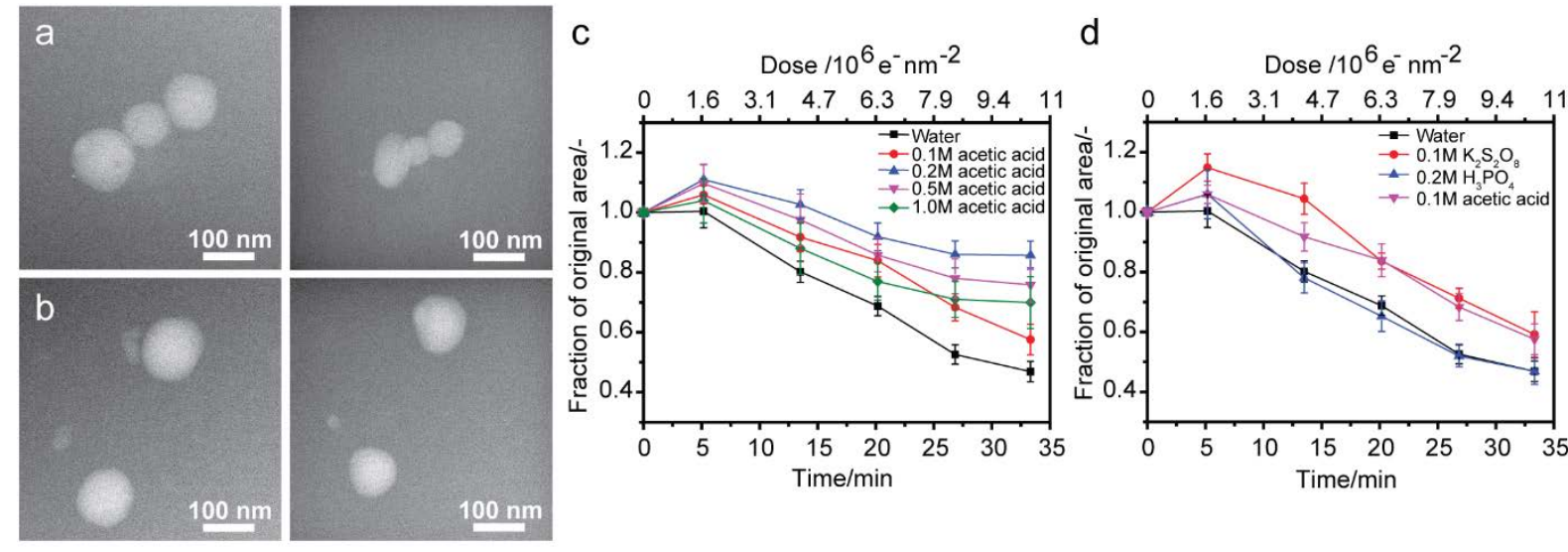

Figure 4. (a-b) HAADF-STEM images of silica nanoparticles calcined at $800{ }^{\circ} \mathrm{C}$ in water (a) and in $0.2 \mathrm{~mol} \mathrm{dm}^{-3}$ acetic acid buffer solution (b) in the liquid cell before (left) and after (right) 33 minutes of electron beam scanning at $225 \mathrm{kx}$ magnification, changing the scanning direction between horizontal and vertical after 5, 13, 20 and 27 minutes. (c) Projected surface area relative to the initial projected surface area, averaged over 10-20 silica particles in solutions with different concentrations of acetic acid buffer as a function of time/electron dose. (d) Projected surface area relative to the initial projected surface area, averaged over 1020 silica particles in solutions with various solutes as a function of time/electron dose. 


\section{WILEY-VCH}
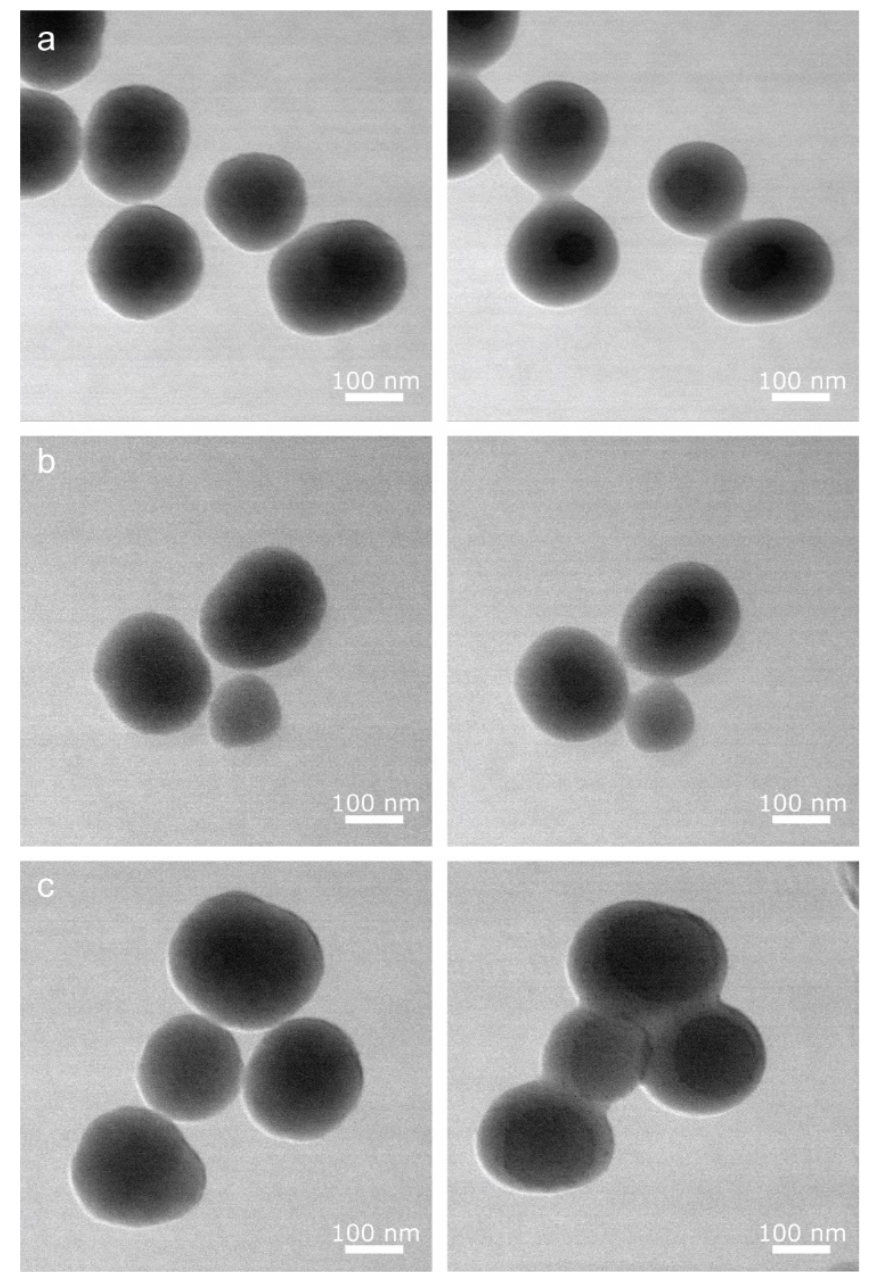

Figure 5. Bright-Field (BF)-STEM images of silica nanospheres calcined at $800{ }^{\circ} \mathrm{C}$, before (left) and after (right) 30 minutes of electron beam scanning at $225 \mathrm{kx}$ magnification. (a) Silica sample as prepared imaged in vacuum, (b) Silica sample dried in the ETEM vacuum for 2 hours at $600{ }^{\circ} \mathrm{C}$ prior to imaging in vacuum and (c) Silica sample dried in the ETEM for 2 hours at $600{ }^{\circ} \mathrm{C}$ prior to imaging in 1 mbar of $\mathrm{H}_{2} \mathrm{O}$ during scanning.

Table 1. N2 physisorption measurements of pore volume and external surface area for the silica samples calcined at different temperatures.

\begin{tabular}{lcccc}
\hline Sample & $\begin{array}{c}\text { BET total } \\
\text { surface area } \\
{\left[\mathrm{m}^{2} \mathrm{~g}^{-1}\right]}\end{array}$ & $\begin{array}{c}\text { Total pore } \\
\text { volume } \\
{\left[\mathrm{cm}^{3} \mathrm{~g}^{-1}\right]}\end{array}$ & $\begin{array}{c}\text { t-plot external surface area } \\
{\left[\mathrm{m}^{2} \mathrm{~g}^{-1}\right]}\end{array}$ & $\begin{array}{c}\text { Surface area based average } \\
\text { particle diameter } \\
{[\mathrm{nm}]}\end{array}$ \\
\hline $400{ }^{\circ} \mathrm{C}$ & 81 & 0.44 & 60 & 23 \\
$600{ }^{\circ} \mathrm{C}$ & 63 & 0.41 & 53 & 26 \\
$800^{\circ} \mathrm{C}$ & 49 & 0.38 & 45 & 30 \\
$1000^{\circ} \mathrm{C}$ & 33 & 0.31 & 31 & 43 \\
\hline
\end{tabular}




\section{WILEY-VCH}

\section{Table of contents entry}

Electron beam-liquid-solid interactions during imaging of silica nanospheres in Liquid Phase Transmission Electron Microscopy are investigated. In this environment, reducing radicals destabilize the silica nanoparticles. Changes in the liquid environment that lower the concentration of those reducing radicals, such as radical scavengers, are shown to result in a large increase in stability of the nanospheres.

\section{Keyword: liquid phase STEM}

Mark J. Meijerink, Cristiano Spiga, Thomas W. Hansen, Christian D. Damsgaard, Krijn P. de Jong, Jovana Zečević*

Nanoscale Imaging and Stabilization of Silica Nanospheres in Liquid Phase Transmission Electron Microscopy
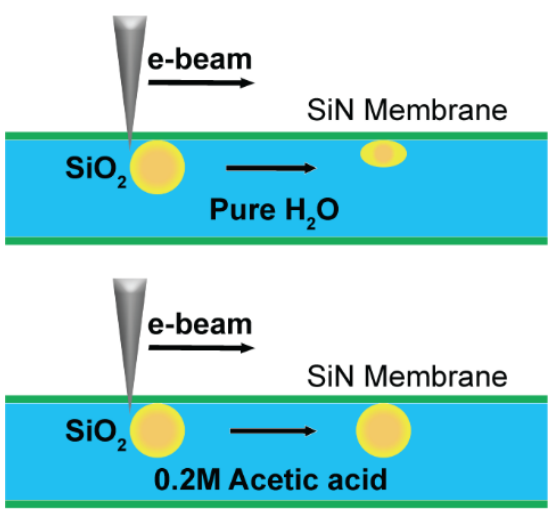